\title{
Prevenção da transmissão de hepatites virais entre manicures e pedicures - uma revisão
}

\author{
Transmission's prevention of viral hepatitis among \\ manicures and pedicures - a review
}

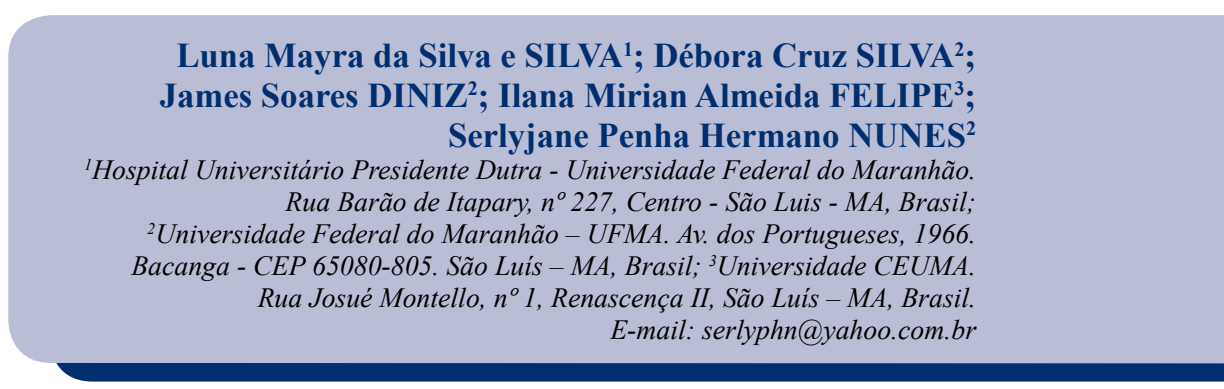

\section{ABSTRACT}

Viral hepatitis is responsible for high rates of morbidity and mortality worldwide, and it requires high investments in their treatments. Hepatitis B and C can often be presented asymptomatically, which results in a high number of infected individuals who are unaware of the fact they have these diseases. Considering that the transmission of these hepatitis forms can be done through the use of contaminated materials, the work materials used by manicures and pedicures can be a means of transmission for these pathogens. Thus, this study aimed to conduct a literature review in order to analyse manicures' and pedicures' information about the possibility of transmission of the causative pathogen from hepatitis and procedures that should be adopted by these workers in order to prevent this transmission. Researches were conducted on Journal Portal Capes and the Scielo and Lilacs databases considering publications in the period between 2003 and 2013. It can be observed in these workers practices a limited knowledge about preventive procedures. Also, the poor adherence to the use of personal protective equipments was noted, as well as, vaccination for hepatitis B. The need for education and training of qualified human resources proved itself to be clear, being indispensable for proper prevention of pathogen transmission from contaminated sharps and cutting materials.

Key Words: Manicure; Pedicure; Hepatitis; Prevention; Transmission

\section{RESUMO}

As hepatites virais são responsáveis por elevadas taxas de morbidade e de mortalidade em todo o mundo e demandam altos investimentos em seus tratamentos. As hepatites B e C podem, frequentemente, apresentar-se de forma assintomática, o que ocasiona uma elevada quantidade de indivíduos infectados que desconhecem o fato de portarem a doença. Considerando que a transmissão de tais hepatites pode ocorrer por meio da utilização de materiais perfurocortantes contaminados, os materiais de trabalho utilizados por manicures e pedicures podem constituir um meio de transmissão de tais patógenos. Desta forma, este estudo teve por objetivo realizar um levantamento bibliográfico a fim de se analisar o conhecimento de manicures e pedicures acerca da possibilidade de transmissão do patógeno causador de hepatites e os procedimentos que devem ser adotados por estes profissionais a fim de prevenirem esta transmissão. Foram realizadas pesquisas no Portal de Periódicos Capes e nas bases de dados Scielo e Lilacs, considerando-se publicações no período de 2003 a 2013. Pode-se observar, dentre as práticas destes profissionais, um baixo conhecimento acerca dos procedimentos preventivos, uma baixa adesão ao uso de equipamentos de proteção individual e à vacinação para hepatite B. A necessidade de formação de recursos humanos capacitados mostrou-se nítida, sendo esta imprescindível para a correta prevenção da transmissão destes patógenos por perfurocortantes contaminados.

Palavras-Chave: Manicure; Pedicure; Hepatite; Prevenção; Transmissão 


\section{INTRODUÇÃO}

As hepatites virais representam, ainda hoje, um relevante problema de saúde pública em todo o mundo, sendo responsáveis por elevadas taxas de morbi-mortalidade, demandando altos investimentos terapêuticos em seus tratamentos (1).

As hepatites B e C podem evoluir em suas formas aguda ou crônica, e apresentar-se de forma sintomática ou assintomática. A frequência da forma assintomática justifica a quantidade de indivíduos que desconhecem o fato de serem portadores da doença, o que favorece o aparecimento das formas mais graves, entre elas a cirrose e o hepatocarcinoma $(1,2,3)$.

Os vírus das hepatites $\mathrm{B}$ e $\mathrm{C}$, HBV e HCV respectivamente, são altamente infecciosos e possuem predileção pelas células hepáticas. Sintomas como a presença de dores nas articulações, fadiga, icterícia, colúria, náuseas e falta de apetite são observados quando evoluem de forma sintomática (4).

As partículas virais do HBV encontram-se mais amplamente distribuídas no sangue, sendo este o fluido corpóreo responsável pela maior transmissão do vírus $(1,5)$. Estes vírus podem, portanto, ser transmitidos por meio de transfusões sanguíneas e hemoderivados contaminados com o vírus; relações sexuais desprotegidas; compartilhamento de agulhas, seringas e outros objetos perfurocortantes; procedimentos que utilizam materiais perfurocortantes quando as normas de biossegurança não são seguidas corretamente, como procedimentos odontológicos, médicos, cirúrgicos, tatuagens, colocação de piercings, procedimentos realizados por manicures e pedicures; transmissão vertical e contatos domiciliares $(2,6)$.

As atividades realizadas por manicures e pedicures requerem a utilização de materiais perfurocortantes, o que consequentemente as torna um grupo vulnerável à contaminação por doenças transmissíveis. Quando realizam a retirada das cutículas pode ocorrer um contato acidental com sangue, fato corriqueiramente observado entre estes profissionais, o que oferece um risco à saúde tanto de manicures e pedicures como dos indivíduos que fazem uso deste tipo de serviço $(7,8)$.

Os materiais de trabalho, utilizados por manicures e pedicures, podem ser contaminados através do contato com sangue do indivíduo atendido, através de pequenos cortes, algumas vezes imperceptíveis. Tais materiais devem ser corretamente esterilizados para que, desta forma, não venham a se constituir como um meio de transmissão parenteral dos vírus das hepatites B e C (8). Sendo assim, os serviços de embelezamento que utilizam materiais que possam ter algum contato com fluidos corpóreos, e que desta forma podem estar, ou ser, conta- minados com os vírus das hepatites $\mathrm{B}$ e $\mathrm{C}$, devem obedecer às normas de biossegurança e adotar procedimentos adequados de limpeza, desinfecção e esterilização dos materiais perfurocortantes, de forma a resguardar a saúde do profissional prestador deste serviço e da população que o utiliza (9).

As profissões de manicures e pedicures foram reconhecidas no Brasil pela Lei 12.592, de 18 de janeiro de 2012, como sendo profissionais que exercem atividades de higiene e embelezamento estético e corporal de indivíduos (10). Considerado como um grupo de profissionais que podem estar expostos a situações de risco, no que tange a contaminação por vírus, não somente das hepatites $\mathrm{B}$ e $\mathrm{C}$, manicures e pedicures requerem uma capacitação adequada, uma vez que a literatura revela um desconhecimento sobre a necessidade de se ter cuidados de biossegurança na prestação deste serviço (7).

O desconhecimento dos prestadores de serviços de manicure e pedicure, não somente do risco ao qual estão expostos, como também das corretas formas de prevenção da contaminação por diversos patógenos, inclusive os das hepatites B e C, e a aparente falta de pesquisas acerca do assunto; fomentou a necessidade de aprofundar esta temática.

\section{MÉTODO}

Trata-se de uma revisão de literatura, realizada por meio de buscas bibliográficas no Portal de Periódicos Capes e nas bases de dados Scielo (Scientific Electronic Library Online) e Lilacs (Literatura Latino-Americana e do Caribe em Ciências da Saúde). Para a determinação das palavras-chaves foram feitas buscas nos Descritores em Ciência da Saúde da Biblioteca Virtual em Saúde (DeCS) e testada a quantidade de resultados que tais descritores em português, e seus sinônimos, geravam.

Foi tomada a decisão de utilizar os seguintes termos para as buscas: Centro de Embelezamento e Estética, Manicure, Pedicure, Hepatite, Hepatite B, Hepatite C, Prevenção, Biossegurança, Esterilização, Infecção, Transmissão, Exposição a Agentes Biológicos, Riscos Ocupacionais. Os termos foram utilizados em combinação nas pesquisas, sempre utilizando o termo "Manicure" ou "Pedicure" em cada busca, a fim de refinarem-se os resultados.

Foram considerados todos os tipos de publicações encontradas nas pesquisas, desde que abordassem a temática do estudo: a atuação profissional de manicures e pedicures relacionada com a disseminação de vírus das hepatites B e C. As publicações deveriam referir-se a menos um dos itens: transmissão e/ou prevenção de hepatites, biossegurança, risco ocupacional, uso de EPI's e vacinação; todos relacionados a profissionais manicures 
e pedicures. Foi delimitado um período de publicações aceitáveis para o estudo, compreendido entre 2003 e 2013.

Os critérios utilizados para exclusão de publicações foram os seguintes: publicações fora da temática do estudo; materiais não disponíveis para acesso on-line; publicações repetidas.

\section{RESULTADOS E DISCUSSÃO}

As buscas direcionaram para: 24 resultados no Portal de Periódicos Capes, 5 resultados na base de dados Scielo e 18 resultados na base de dados Lilacs. Os artigos e manuais encontrados foram analisados pelos seus títulos e respectivos resumos e destes excluíram-se, os que não se enquadravam na temática do estudo, os que não possuíam acesso de conteúdo integral on-line e os que haviam sido publicados em línguas que não fossem o português ou o inglês. Para os artigos que haviam aparecido em mais de uma busca, considerou-se somente um. Foram excluídos: uma dissertação por possuir um artigo original já publicado que foi inserido na pesquisa, e um artigo publicado em periódico por estar publicado em um idioma cuja leitura e compreensão não foram possíveis.

Desta forma, foram incluídos na pesquisa $7 \mathrm{pu}-$ blicações, sendo 5 artigos publicados em periódicos e 2 manuais. Dos 5 artigos selecionados (Quadro 1), 3 foram resultados de buscas no Portal de Periódicos Capes, 1 foi resultado de busca na base de dados Lilacs e 1 foi resultado de busca na base de dados Scielo.

Quadro 1: Listagem dos artigos analisados segundo a ordem de títulos, autores, ano de publicação, periódico, sobre o tema transmissão de hepatite viral em manicures e pedicures.

\begin{tabular}{|l|l|l|l}
\hline \multicolumn{1}{|c|}{ TITULO } & \multicolumn{1}{c|}{ AUTOR } & ANO & \multicolumn{1}{c|}{ PERIÓDICO } \\
\hline $\begin{array}{l}\text { Assessment of knowledge and practice of Barbers \& Beauti- } \\
\text { cians regarding Hepatitis B and C. }\end{array}$ & Khan MI, et al. & 2012 & $\begin{array}{l}\text { Gomal Journal of Medical } \\
\text { Sciences. }\end{array}$ \\
\hline $\begin{array}{l}\text { Biossegurança e risco ocupacional entre os profissionais do } \\
\text { segmento de beleza e estética: revisão integrativa. }\end{array}$ & Garbaccio J, et al. & 2012 & Rev Eletr Enf. \\
\hline $\begin{array}{l}\text { Hepatite B: conhecimento dos riscos e adoção de medidas } \\
\text { de biossegurança por manicures/pedicures de Itaúna-MG. }\end{array}$ & Moraes JT, et al. & 2012 & R Enferm Cent 0 Min. \\
\hline $\begin{array}{l}\text { Procedimentos de biossegurança adotados por profissionais } \\
\text { de serviços de embelezamento. }\end{array}$ & Diniz A F, et al. & 2013 & Saúde Soc São Paulo. \\
\hline $\begin{array}{l}\text { Survey of hepatitis B and C infection control: procedures at } \\
\text { manicure and pedicure facilities in São Paulo, Brazil. }\end{array}$ & Oliveira ACDS, et al. & 2010 & Braz J Infect Dis.
\end{tabular}

Os dois manuais (Quadro 2) selecionados foram provenientes da base de dados Lilacs.

As pesquisas mostraram dados acerca do nível de conhecimento de manicures e pedicures a respeito: da transmissão das hepatites B e C por meio de suas atividades profissionais e dos métodos de prevenção desta transmissão.

Quadro 2: Listagem dos manuais analisados segundo a ordem de títulos, órgãos autores, ocal e ano, sobre o tema transmissão de hepatite viral em manicures e pedicures.

\begin{tabular}{|l|l|c|c|}
\multicolumn{1}{c|}{ TÍTULO } & \multicolumn{1}{c|}{ ÓRGÃO AUTOR } & LOCAL & ANO \\
\hline $\begin{array}{l}\text { Manual de orientação para instalação e } \\
\text { funcionamento de institutos de beleza } \\
\text { sem responsabilidade médica. }\end{array}$ & $\begin{array}{l}\text { Secretaria de Estado da Saúde de São Paulo. Coorde- } \\
\text { nação de Controle de Doenças. Centro de Vigilância } \\
\text { Sanitária }\end{array}$ & São Paulo & 2009 \\
\hline $\begin{array}{l}\text { Beleza com segurança: guia técnico para } \\
\text { profissionais. }\end{array}$ & $\begin{array}{l}\text { Secretaria de Saúde do Município de São Paulo. } \\
\text { Coordenação de Vigilância em Saúde }\end{array}$ & São Paulo & 2009 \\
\hline
\end{tabular}

O estudo realizado por Oliveira e Focaccia (2010), com 100 manicures e pedicures, em São Paulo, observou que a maioria destes profissionais desconhecia os riscos de contaminação, pelos vírus das hepatites, aos quais ficavam expostos durante a realização das atividades profissionais. Dentre estes profissionais, $93 \%$ afirmaram não saber como se prevenir da hepatite $\mathrm{B}$ e $95 \%$ desconheciam como se prevenir da hepatite $\mathrm{C}$ (11). 
Moraes et al (2012) observaram em sua pesquisa, que das 127 manicures estudadas em Itaúna, MG, $3,1 \%$ nunca tinham ouvido falar em hepatite B e 20,5\% desconheciam as formas de transmissão da doença. Os dados encontrados por esses pesquisadores com relação ao desconhecimento das formas de transmissão das hepatites são menores que os encontrados por Oliveira e Focaccia (2010), mas mesmo assim representam uma situação que requer adequada atenção $(11,12)$.

Em Jacareí, SP foi observado que 55\% dos profissionais entrevistados tinham conhecimento a respeito da transmissão das hepatites. Do total destes profissionais $57,5 \%$ afirmaram saber que tais doenças podem ser transmitidas por meio de seus instrumentos de trabalho (13).

Os dados demonstram uma notável falta de conhecimento destes profissionais acerca da transmissão das hepatites B e C, o que reflete em um desconhecimento da dimensão dos riscos ocupacionais aos quais estão expostos.

Os riscos de transmissão podem ser diminuídos com a adoção de práticas e medidas de biossegurança, desde que estas sejam executadas de forma correta, resguardando a saúde do profissional e das pessoas por eles atendidas (14). As medidas de biossegurança adotadas pelos profissionais manicures e pedicures durante o exercício de suas profissões foram observadas pelas pesquisas analisadas neste estudo.-

A redução do risco de exposição aos vírus das hepatites $\mathrm{B}$ e $\mathrm{C}$ pode ser alcançada com uma medida simples, e que possui notável importância, a correta lavagem das mãos. Esta prática deve ter cunho indispensável entre manicures e pedicures, levando-se em conta que nestes profissionais as mãos estão em constante contato com os clientes e expostas a possíveis contatos com microrganismos $(15,16,17)$.

Mais da metade dos profissionais estudados por Oliveira e Focaccia (2010), cerca de 70\%, relataram que possuem o hábito de lavar as mãos no intervalo entre o atendimento de um cliente e outro. Porém, em tal pesquisa observou-se que nenhum dos profissionais que afirmou lavar as mãos realizou a lavagem das mãos durante o período em que os pesquisadores observaram suas atuações profissionais. Destes profissionais, $66 \%$ chegaram a relatar que o hábito de lavar as mãos, como medida de higiene, não constitui uma forma de prevenção de infecções (11).

Moraes et al (2012) observaram que dos profissionais participantes de seu estudo, 72,4\% afirmaram lavar as mãos antes e após a realização dos procedimentos em suas clientes e $26 \%$ afirmaram não possuírem o habito de lavar as mãos (12).

O local de trabalho de manicures e pedicures deve possuir uma estrutura que permita o fácil acesso a pias e a demais utensílios necessários para a realização da correta higienização das mãos dos profissionais, como sabão e papel toalha $(16,17,18)$. Porém, isto não se reflete na realidade observada por Oliveira e Focaccia (2010), pois dos salões de belezas analisados na cidade de São Paulo, SP, nenhum apresentou tal estrutura (11). Diniz e Matté (2013) também constataram que os salões em sua maioria não possuem uma estrutura física adequada, uma vez que em sua pesquisa observou que somente $7,5 \%$ destes possuíam pias para a lavagem de mãos dos profissionais localizadas próximas do local de atendimento dos clientes (13).

O Ministério do Trabalho, em sua Norma Regulamentadora $-\mathrm{NR} \mathrm{n}^{\mathrm{o}} 6$, define os equipamentos de proteção individual - EPI como sendo todo dispositivo ou produto, de uso individual, utilizado pelo trabalhador, destinado à proteção de riscos suscetíveis de ameaçar a segurança e a saúde no trabalho. Estes equipamentos não são destinados somente a garantir a proteção destes profissionais, mas também possuem papel importante na diminuição do risco de transmissão de microrganismos durante o exercício da profissão $(11,19)$.

A transmissão de microrganismos e/ou contaminação das manicures e pedicures por tais patógenos pode ser evitada com a utilização de luvas, uma vez que estas funcionam como barreiras físicas, impedindo desta forma o contato de microrganismos com as mãos dos profissionais. Recomenda-se o uso de luvas sempre que existir a possibilidade de contato com sangue, ou demais fluidos corpóreos, provindos de mucosas ou pele não íntegra; ou a possibilidade de contato e manuseio de materiais que podem estar sujos de sangue ou demais fluidos. Ressalta-se que equipamentos de proteção devem ser desprezados após o uso em cada cliente, não podendo, portanto, haver a reutilização destes $(14,17,20)$.

O Ministério da Saúde elaborou um folheto educativo destinado para profissionais que trabalham com produtos e serviços de beleza, que recomenda o uso de luvas descartáveis durante os procedimentos realizados por manicures e pedicures e o uso de luvas de borracha para a realização da limpeza dos instrumentos. Todas estas recomendações possuem o intuito de minimizar os riscos que podem ser resultado de possíveis acidentes ocupacionais, durante o manuseio de materiais perfurocortantes (14).

Dos profissionais que participaram do estudo realizado em São Paulo, SP, 84\% reconheceram a necessidade da utilização de luvas e a importância de tal prática para a proteção do profissional e dos clientes, porém $80 \%$ dos profissionais afirmaram não utilizar luvas em suas práticas de trabalho. Notou-se, porém, que dos $20 \%$ que afirmaram utilizar luvas, somente 5\% realmente a utilizaram durante os procedimentos (11). 
Moraes et al (2012) relataram que em Itaúna, MG, $87,4 \%$ dos profissionais participantes do estudo afirmaram que utilizam luvas descartáveis para cada cliente atendida. Diniz e Matté (2013) observaram em sua amostra de estudo que $50 \%$ dos profissionais de sua pesquisa afirmaram não utilizar luvas durante os procedimentos de trabalho, e dos que utilizaram, na maioria dos casos, não realizavam o correto descarte, sendo tais instrumentos utilizados para vários clientes $(12,13)$.

Percebeu-se que embora alguns dos profissionais relatem ter conhecimento acerca da importância e da necessidade da utilização de luvas, não a utilizam. O fato de não utilizarem as luvas foi justificado de diversas maneiras, como o fato da luva atrapalhar a execução dos procedimentos e a falta de costume com elas $(11,13$, 21).

Quase metade dos profissionais participantes de uma pesquisa realizada em Jacareí relatou a ocorrência de contato com sangue de clientes quando não estavam utilizando luvas. A falta da utilização de luva observada no estudo justificou os eventos em que os profissionais tiveram contato direto com sangue das pessoas atendidas (13).

Após a exposição a materiais biológicos, é de extrema importância o tratamento imediato da superfície exposta. É recomendado que seja realizada a lavagem da área exposta com água e sabão imediatamente (20).

Quando questionados a respeito de quais procedimentos eram adotados por tais profissionais após o contato com sangue das pessoas atendidas, os profissionais relataram diversos procedimentos diferentes, como: lavagem das mãos; utilização de álcool; utilização de acetona; a limpeza das mãos utilizando-se as mesmas toalhas utilizadas durante o atendimento dos clientes; e outros procedimentos errados. Houve também profissionais que relataram não realizar qualquer ação. Observou-se, portanto, uma ausência de protocolo a ser seguido após a exposição a uma hemorragia ocasional durante a execução de seus trabalhos $(11,13,21)$.

A vacina contra a hepatite B é uma forma profilática eficiente constituída de um esquema composto de três doses. A vacinação é realizada de forma gratuita, pelo Sistema Único de Saúde e destinada a pessoas com idade igual ou inferior a 29 anos e a grupos com maior vulnerabilidade de exposição à infecção, neste grupo encontram-se diversos profissionais e entre estes estão incluídos manicures e pedicures $(3,6,14,22,23)$.

Os estudos realizados demonstraram que grande parte dos profissionais não possui conhecimento da importância da vacina como medida de prevenção. Moraes et al (2012) descreveu em seu estudo que mais de $60 \%$ dos profissionais afirmaram terem sido vacinados contra hepatite B, porém, destes, somente $37,2 \%$ estavam com o esquema vacinal completo, os demais afirmaram não ter tomado as três doses ou não lembravam (12).

Uma análise realizada na cidade de Bahawalpur, no Paquistão, mostrou que apenas $24 \%$ dos entrevistados haviam tomado vacina contra hepatite B (24). Outros estudos, envolvendo outras classes de profissionais, também evidenciaram o desconhecimento da necessidade da vacinação contra hepatite $B$, em seu esquema completo de três doses, a fim de assegurar a prevenção contra esta doença $(25,26)$.

Os materiais utilizados na prática profissional de manicures e pedicures entram em contato com material biológico, mesmo que algumas vezes de formas imperceptíveis, o que implica na necessidade de uma correta higienização ou descarte desses materiais após o uso $(11,17)$.

Segundo o Ministério da Saúde, os objetos metálicos classificados como artigos críticos, que são objetos de natureza perfurocortante (alicates de cutículas, curetas, afastadores de cutículas, dentre outros) devem ter um tratamento específico após o uso, a esterilização; já os artigos não críticos de uso permanente (tigelas utilizadas para colocar água com finalidade de amolecer as cutículas das unhas das mãos ou dos pés) devem ser lavados de forma correta, com água e sabão a cada atendimento, e devem ser protegidos por protetores plásticos aserem descartados após o uso, ou, em caso de não uso dos protetores plásticos, tais utensílios devem ser desinfetados com álcool $70 \%(14,17,27)$.

A desinfecção é o método que tem capacidade de eliminar microrganismos patogênicos, com a utilização de métodos químicos, porém sem eliminação dos mais resistentes, os esporos. Já a esterilização é um processo que pode ser químico, físico ou físico-químico, capaz de eliminar todas as formas de vida microbianas $(17,28)$.

O estudo de Diniz e Matté (2013) mostrou que $67,5 \%$ das manicures e pedicures pesquisadas afirmaram ter conhecimento a respeito do que era esterilização e que entre os equipamentos mais comumente utilizados por estes profissionais, com tal finalidade, encontravam-se a autoclave, a estufa e, em sua maioria, o forninho. Observou-se que $10 \%$ destes forninhos não possuíam termômetros ou termostatos (13).

Em outro estudo, foi observado que o uso de estufa para esterilização mostrou-se majoritário, representando $83 \%$ dos casos. Em segundo lugar o uso de autoclave, com $11,3 \%$ dos casos (12). Oliveira e Focaccia (2010) observaram que em salões de beleza localizados em centros comerciais o uso de autoclave é predominante, representando $68 \%$. Enquanto os salões de beleza que estavam localizados fora de centro comerciais apresentaram o uso de forninhos em sua maioria, $60 \%$ (11). 
Outros métodos distintos e não descritos em literatura como métodos de eficácia comprovada foram relatados pelos profissionais, com finalidade de esterilização, como: uso de panela de pressão, álcool, álcool e água fervente, formol e um composto a base de quaternário de amônio e formol $(12,21,24)$.

Foram observadas muitas falhas durante a execução do processo de esterilização, dentre elas: a abertura do aparelho antes do fim do processo; o desconhecimento da temperatura a qual o equipamento atingia; a utilização de tempo e temperatura diferentes dos preconizados. Percebeu-se, portanto, que em todas as pesquisas realizadas a maioria dos profissionais não tinha conhecimento do tempo e da temperatura que deveriam ser utilizadas para a correta esterilização dos materiais perfurocortantes. Notou-se a ausência de padronização na realização de tais procedimentos, o que prejudica e/ ou interfere na eficácia dos processos de esterilização (11-13,21).

Para que os processos de esterilização sejam efetivos, o tempo e a temperatura aplicada nos processos devem ser rigorosamente obedecidos. O Ministério da Saúde determina que em caso da utilização de estufa seja utilizada a temperatura de $160^{\circ} \mathrm{C}$ durante um período de duas horas, ou $170^{\circ} \mathrm{C}$ durante uma hora. Já em casos de utilização de autoclaves recomenda-se que temperatura e duração do processo sigam as recomendações estabelecidas pelo fabricante $(14,16,29)$.

Uma correta esterilização dos materiais perfurocortantes deve ser precedida de uma lavagem com água e sabão, realizando-se a limpeza dos materiais com uma escova de cerdas macias para remoção de sujidades em áreas de difíceis acessos. Esta limpeza representa uma importante etapa possibilitando a ação do agente esterilizante $(14,17,20)$.

Os estudos mostraram que esta limpeza nem sempre é realizada e que muitas vezes os profissionais confundem a limpeza com a desinfecção e até mesmo com a esterilização. Tais fatos corroboram a necessidade de capacitação desse grupo de profissionais $(11,12)$.

Diversos métodos de limpeza e de desinfecção foram descritos por manicures e pedicures, dentre os que não possuem comprovação de eficácia, pode-se citar: fricção manual com algodão umedecido em acetona, fricção manual em água corrente, fricção manual com algodão seco, fricção manual em água e fricção com algodão umedecido em álcool, molho em cloro e outros (12).

Observou-se, uma tentativa dos profissionais de diminuir o compartilhamento de instrumentos de uso individual, realizando-se a recomendação de que os clientes levem seu próprio conjunto de instrumentos para o salão, porém observou-se que, em sua maioria, os clientes não possuíam o hábito de levar seus instrumentos pessoais. Tal prática isentaria a necessidade do compartilhamento de materiais perfurocortantes e, reduziria, assim, o risco de transmissão das hepatites $\mathrm{B}$ e C $(11,12)$.

Durante a realização das atividades profissionais de manicures e pedicures é necessária a utilização de alguns materiais de uso único, como: protetores plásticos para bacias para mãos e pés; lixas para unhas; lixas para pés; palitos de madeira; e espátulas de madeira. Estes materiais devem ser descartados após cada uso, uma vez que não podem ser esterilizados ou higienizados de forma adequada $(14,17)$.

Em todos os estudos foi observado, em porcentagens que variam de aproximadamente $30 \%$ a $93 \%$, a reutilização de materiais descartáveis. Os maiores números foram encontrados na pesquisa realizada por Oliveira e Focaccia (2010), onde 93\% dos profissionais manicures e pedicures afirmaram reutilizar lixas de unha, palitos de madeira e sacos plásticos utilizados como proteção de bacias e pias $(11,12,13,21,24)$.

Todos os estudos evidenciaram uma carência de conhecimento e de conscientização de manicures e pedicures com relação aos riscos ocupacionais que estão expostos e acerca da necessidade de implementação de práticas preventivas $(11,12,13,24)$.

A carência de cursos de capacitação regulamentados, o número insuficiente de treinamento de manicures e pedicures e a informalidade permitem que estes profissionais desempenhem suas funções sem o devido conhecimento para que possam exercer seu trabalho de forma segura (21).

Acredita-se, portanto, que para que haja um maior conhecimento, por parte destes profissionais acerca das formas de transmissão e prevenção da doença se faz necessário uma intensificação das informações acerca do tema, com uma maior divulgação através de materiais informativos (30).

Por ser considerado um problema de saúde pública, a criação de um programa específico de prevenção e controle das hepatites, destinado aos profissionais manicures e pedicures é de suma importância devido a possibilidade de transmissão. Desta forma, programas preventivos são imprescindíveis, mas com foco não somente voltados para estes profissionais, mas também para a população em geral que se utiliza dos serviços prestados por estes profissionais.

\section{CONCLUSÃO:}

As práticas exercidas por profissionais manicures e pedicures constituem riscos de transmissão dos vírus das hepatites B e C, tanto de cliente para profissional, de cliente para cliente, como também de profissional para cliente. 
Embora existam muitas recomendações acerca da prevenção e da execução de práticas seguras durante o exercício da profissão, observa-se que estas práticas não são executadas. Seja por falta de conhecimento destas recomendações, pela ausência de hábito de executá-las, ou pelo exercício incorreto de práticas preventivas sugere a criação de normas técnicas específicas que norteiem a atividade profissional, como também a fiscalização, por órgãos públicos competentes.

A formação de profissionais capacitados deve ser proporcionada ou incentivada com a criação de cursos preparatórios capazes de treinar e de conscientizá-los acerca dos riscos ocupacionais aos quais estão expostos. Observa-se ainda a necessidade de realização de campanhas de incentivo à vacinação para hepatite $\mathrm{B}$ e a detecção de soroconversão com dosagem de anticorpos protetores após a imunização, além da sensibilização para promover uma mudança comportamental com o intuito de proteger a saúde de manicures e pedicures e da população em geral.

\section{REFERÊNCIAS}

1. Hou J, Liu Z, Gu, F. Epidemiology and Prevention of Hepatitis B Virus Infection. Int J Med Sci. 2005; 2(1):50-57.

2. Alter MJ. Epidemiology of hepatitis $\mathrm{C}$ in the west. Semin Liver Dis. $1995 ;$ 15(1):5-14.

3. Ferreira CT, Silveira TR. Hepatites virais: aspectos da epidemiologia e da prevenção. Rev Bras Epidemiol. 2004; 7(4):473-487.

4. Cottone JÁ, Puttaiah R. Hepatitis B virus infection: current status in Dentistry. Dent Clin North Am. 1996; 40(2):293-307.

5. Rapparini C, Vitória MAA, Lara LTR. Recomendações para atendimento e acompanhamento de exposição ocupacional a material biológico: HIV e hepatites B e C. [Acesso em 23 dezembro 2013]. Disponível em: http://bvsms.saude.gov.br/bvs/ publicacoes/04manual_acidentes.pdf .

6. BRASIL. Ministério da Saúde. Secretaria de Vigilância em Saúde. Departamento de Vigilância Epidemiológica. Hepatites Virais: O Brasil está atento. $3^{\mathrm{a}}$ ed. Brasília; 2008.

7. Cortelli AFD. Procedimentos de biossegurança adotados por profissionais prestadores de serviços de manicure, pedicure, tatuagem, piercing e maquiagem definitiva no município de Jacareí-SP. [Dissertação]. São Paulo: Faculdade de Saúde Pública da Universidade de São Paulo. 2012.

8. Mariano A, Mele A, Tosti ME, Parlato A, Gallo G, Ragni P, Zotti C, Lopalco P, Pompa MG, Graziani G, Stroffolini T. Role of beauty treatment in the spread of parenterally transmitted hepatitis viruses in Italy. J Med Virol. 2004; 74(2):216-220.

9. Johnson IL, Dwyer JJM, Rusen ID, Shahin R, Yaffe B. Survey of infection control: procedures at manicure and pedicure establishments in North York. Can J Public Health. 2001; 92 (2): 134-137.

10. BRASIL. Lei 12.592 , de 18 de janeiro de 2012. Dispõe sobre o exercício das atividades profissionais de Cabeleireiro, Barbeiro, Esteticista, Manicure, Pedicure, Depilador e Maquiador. Diário Oficial da União. 19 janeiro 2012.

11. Oliveira ACDS, Focaccia R. Survey of hepatitis B and C infection control: procedures at manicure and pedicure facilities in São Paulo, Brazil. Braz J Infect Dis. 2010; 14(5):502-507.

12. Moraes JT, Barbosa FI, Costa TRS, Ferreira AF. Hepatite B: Conhecimento dos riscos e adoção de medidas de biossegurança por manicures/pedicures de Itaúna-MG. R Enferm Cent O Min. 2012; 2(3):347-357.

13. Diniz AF, Matté GR. Procedimentos de biossegurança adotados por profissionais de serviços de embelezamento. Saúde Soc São Paulo. 2013; 22(3):751-759.
14. BRASIL. Ministério da Saúde. Folheto publicitário: Hepatite B e C são doenças silenciosas - veja como deixar as hepatites longes do seu salão de beleza. [Acesso em 18 dezembro 2013]. Disponível em: http://www.senac.br/senac/Folheto Hepatite 11 21 Manicure_SENAC.pdf

15. BRASIL. Ministério da Saúde. Agência Nacional de Vigilância Sanitária. Higienização das mãos em serviços de saúde. Brasília: Anvisa; 2007.

16. PMSP. Prefeitura Municipal de São Paulo. Secretaria de Saúde do Município de São Paulo. Coordenação da Vigilância em Saúde. Beleza com segurança: guia técnico para profissionais. São Paulo (SP); 2009.

17. SP. Secretaria de Estado da Saúde de São Paulo. Coordenação de Controle de Doenças. Centro de Vigilância Sanitária. Manual de orientação para instalação de funcionamento de institutos de beleza sem responsabilidade médica. 2012.

18. SEBRAE. Exigência da Vigilância Sanitária para salão de beleza: Beleza com segurança. Elaborado por: Sandra Regina Bruno Fiorentini. São Paulo; 2009. [Acesso em 27 dezembro 2013]. Disponível em: http://www.hairbrasil.com/congresso/sebrae 2009/ fiorentini.pdf

19. BRASIL. Ministério do Trabalho e do Emprego. Normas Regulamentadoras de Segurança e Saúde no Trabalho. NR 6 - Equipamentos de proteção individual - EPI. Diário Oficial da União, 6 jul. 1978. [Acesso em 23 dezembro 2013]. Disponível em: http://portal.mte.gov.br/data/files/8A7C812D3 6A2800001388130953C1EFB/NR-06\%20(atual izada)\%20 2011.pdf.

20. BRASIL. Agência Nacional de Vigilância Sanitária. Curso básico de controle de infecção hospitalar. Caderno C: Métodos de Proteção anti-infecciosa. Brasília (DF); 2000.

21. Garbaccio JL, Oliveira AC. Biossegurança e risco ocupacional entre os profissionais do segmento de beleza e estética: revisão integrativa. Rev Eletr Enf. 2012; 14(3):702-711.

22. Cavalcanti FM, Melo RGSV, Patrício DPS, Zimmermann RD. Hepatite B: conhecimento e vacinação entre os acadêmicos da Faculdade de Odontologia de Caruaru - PE. Rev Odontol Clin Cientif. 2009; 8(1):59-65.

23. BRASIL. Ministério da Saúde. Programa Nacional para a Prevenção e Controle das Hepatites Virais: Manual de aconselhamento em hepatites virais. Brasília (DF); 2005. 
24. Khan MI, Zhaidi AA, Mehar A, Ahmed R, Zahoor S, Sarfaraz A Safdar MS. Assessment of knowledge and practice of barbers \& beauticians regarding hepatitis B and C. Gomal Journal of Medical Sciences. 2012; 10(1).

25. Soriano EP, Carvalho MVD, Carneiro GR, Guimarães LL, Santos FB. Hepatite B: avaliação de atitudes profiláticas frente ao risco de contaminação ocupacional. Rev Odontol Clin Cientif. 2008; 7(3):227-234.

26. Martins AMEBL, Barreto SM. Vacinação contra a hepatite B entre cirurgiões dentistas. Rev Saude Publica. 2003; 37(3):333-338.

27. SEBRAE. Dicas Sebrae: Salão de beleza. Postura profissional e normas técnicas. Elaborado por: Adriany Rosa de Matos Carvalho. Recife (PE); 2010. [Acesso em 27 dezembro 2013]. Disponível em: http://189.39.124.147:8030/downloads/salao-normas-tecnicas.pdf
28. BRASIL. Agência Nacional de Vigilância Sanitária. Resolução $\mathrm{RE} \mathrm{n}^{\circ}$ 2.606, de 11 de agosto de 2006. Dispõe sobre as diretrizes para elaboração, validação e implantação de protocolos de reprocessamento de produtos médicos e dá outras providências. Diário Oficial da União. 14 ago 2006.

29. BRASIL. Ministério da Saúde. Secretaria de Assistência à Saúde. Coordenação de Controle de Infecção Hospitalar. Processamento de Artigos e Superfícies em Estabelecimentos de Saúde. 2.ed. Brasília: Ministério da Saúde, 1994.

30. Melo FCAD, Isolani AP. Hepatite B e C: do risco de contaminação por materiais de manicure/pedicure à prevenção. SaBios: Rev Saúde Biol. 2011; 6(2):72-78. 